\section{Science policy in Australia}

SiR-The Australian federal government has placed great emphasis on science and technology to underpin Australia's future economic performance. A recent policy statement on higher education describes the government's agenda for sweeping changes designed to align academic and

Table 1 Career prospects

Perceptions of career prospects in science in Australia as poor

\begin{tabular}{lr}
\hline 1. Overall & $80 \%$ \\
2. Nationality & \\
$\quad$ Australian & $79 \%$ \\
non-Australian & $80 \%$ \\
3. Experience (yrs post-PhD) & \\
$<3 \mathrm{yr}$ & $82 \%$ \\
$3-5 \mathrm{yr}$ & $68 \%$ \\
$>5 \mathrm{yr}$ & $86 \%$ \\
Expectation of tenurable next appointment \\
1. Overall \\
2. Experience (yrs post-PhD) \\
$<3 \mathrm{yr}$ \\
$3-5 \mathrm{yr}$ \\
$>5 \mathrm{yr}$ & $5 \%$ \\
& $18 \%$ \\
\hline
\end{tabular}

research performance to national economic goals, which requires a dramatic expansion of Australia's capacity to produce graduates, particularly in science and technology. The success of this strategy depends on the ability to attract the brightest young minds to careers in scientific research.

\section{Too much secrecy}

SIR-I would like to add to the letter from A. Thyagaraja (Nature 335, 391; 1988) some observations based on my own experience of writing and refereeing papers over the past 30 years or so.

On the relatively rare occasions when I have received signed referees' reports, they have been cogently expressed and I have welcomed them, irrespective of whether they were favourable or not. Unfavourable anonymous reports are less welcome. I have often found them difficult to reply to, because they tend to be cryptic if not incomprehensible; anonymity seems to invite a casual approach.

At the risk of sounding self-righteous, I cannot recall ever writing an anonymous report; my name may have been removed by the editor in some instances, but not at my request.

If I think a paper is unsatisfactory by reason of, for example, length, confused presentation, insufficient or excessive supporting data or inadequate diagrams, I write to the authors wherever possible and send a copy to the editor. Only once did an author take exception to this. He complained to the editor, who adjucated (in
A fundamental flaw in the government's new policy is its failure to address existing problems in the training and retention of research scientists in productive research careers. Cutbacks in research and higher educatior, spending over the past ten years have significantly reduced the number of continuing positions available, leading to a 'bottleneck' between non-tenured and continuing appointments. Young scientists are forced either to spend longer in short fixed-term positions or to leave research and seek employment in fields that offer better prospects for career advancement.

In July-August 1988, we conducted a survey of the attitudes of non-tenured scientists at the Australian National University (ANU) in Canberra. A total of 194 non-tenured research staff ( 94 per cent of all non-tenured scientists at the ANU) were surveyed, spanning the disciplines of physics (24 per cent), chemistry (21 per cent), biology (37 per cent), medicine (10 per cent), Earth sciences ( 4 per cent) and mathematics (4 per cent). The response was high ( 70 per cent). The respondents had varying amounts of postdoctoral experience, ranging from less than three years ( 29 per cent), $3-5$ years ( 32 per cent) and greater than five years ( 39 per cent). An overwhelming majority of nontenured scientists were pessimistic about their future prospects in Australian research, describing them as "poor"

my favour, as it happens, but at least the author had an identifiable target).

In nearly every case, authors have responded thoughtfully and courteously, adopting some of my suggestions, rejecting others, always with sound explanations for their actions. I think the result has been to improve the quality of the papers. (Sometimes I even get a mention in the acknowledgements.) Where it has been necessary to reject a paper, I have always provided a full explanation, so that the author(s) can come back to me direct.

Nobody has yet presented me with a convincing argument in favour of anonymous refereeing, and that includes practising scientists as well as journal editors. Quite simply, I do not believe there is one.

Most vulnerable to anonymous refereeing are those working in controversial or rapidly developing fields, especially if they are young and trying to make a name for themselves. Show me a scientist who favours anonymous refereeing and I will show you someone who is insecure. That is my opinion, after some 30 years' experience. What do other people think?

Department of Earth Sciences,

Open University, Walton Hall,

Milton Keynes, MK76AA, UK
(Table 1). The survey indicated a very high level of dissatisfaction with career structures at present available to Australian researchers (Table 2). Sixty-one per cent of respondents were prepared to leave Australian research (Table 2). The Australian National University is often regarded as the 'showpiece' of the Australian university system with respect to its research effort. We believe the results of this survey reflect the situation faced by the majority of non-tenured scientists in Australian universities.

Our survey indicates one likely consequence of a continuing lack of career opportunities in Australian research. In the near term, many talented young scientists will leave the Australian system (see Table 2), either to continue research careers in other countries, or to find employment with better career prospects outside research. Another likely conse-

\section{Table 2 Attitudes}

Dissatisfaction with present career structures in Australian science

1. Overall

2. Nationality

Australian non-Australian

$91 \%$

perience (yrs post- $\mathrm{PhD}$ )

$<3 \mathrm{yr}$

$3-5 \mathrm{yr}$

$>5 \mathrm{yr}$

Prepared to leave Australian research
1. Overall
2. Nationality
Australian
$61 \%$
$59 \%$
non-Australian
$78 \%$

quence is that high-quality graduates will be dissuaded from pursuing careers in scientific research. In the longer term, this loss of talent will result in Australia's research and development effort failing to provide the technological base for the planned revitalization of the Australian economy.

Solutions can be found to the problems highlighted by our survey. It is vital to increase funding for research and higher education. Moreover, the first step must be to address the existing problems with career structures. More continuing appointments, based on merit, must be made to retain young scientists and to recruit prospective students to careers in research.

M. K. Morell
G. D. Price
K. C. WoO

K. C. WOO

A. B. Wellington

Research School of Biological Sciences,

Australian National University,

PO Box 475,

Canberra,

ACT 2601,

Australia 